\title{
The Use of the Thionin Blue Sensitivity Test in the Examination of Brucella
}

\author{
By W. J. B. MORGAN \\ Central Veterinary Laboratory, Weybridge, Surrey
}

(Received 24 November 1960)

\begin{abstract}
SUMMARY
A total of 171 cultures of Brucella, mostly isolated in this country from milk and foetal material, was examined for sensitivity to thionin blue as well as to basic fuchsin and thionin, and for agglutination in monospecific sera. Standard strains of Brucella abortus, B. melitensis and B. suis grew in the presence of thionin blue in the concentration studied. Three groups of $B$. abortus were found, however, which were sensitive to thionin blue. These were: $(a)$ strains resembling the vaccine strain $B$. abortus strain 19; (b) dye sensitive strains ( $B$. abortus type II Wilson), (c) a previously undescribed group. Cultures of this last group required added $\mathrm{CO}_{2}$ for growth, grew on basic fuchsin and were virulent for guinea-pigs. The significance of these results is briefly discussed.
\end{abstract}

\section{INTRODUCTION}

McLeod (1944) reported that Brucella abortus strain 19 would not grow on media containing thionin blue in concentrations that would allow the growth of other strains of $B$. abortus. This observation was confirmed by Levine \& Wilson (1949) and Cruickshank (1954). The latter author also pointed out that strains of $B$. abortus type II Wilson (Huddleson, 1955) did not grow on thionin blue media. These strains are known to be very sensitive to dyes and require the presence of serum or Tween 40 for growth (Huddleson, 1956; Sackman, 1957; Morgan, 1960). The purpose of the present paper is to record the results of the examination of Brucella cultures for sensitivity to thionin blue.

\section{METHODS}

Organisms. Most of the organisms studied were isolated at this Laboratory from foetal material or milk; the remainder had been sent in for confirmation of identity. Except for recently isolated cultures, they were all checked for dissociation by using obliquely transmitted light (Henry, 1933) and only smooth cultures were studied.

Media. Serum glucose agar was used for the propagation of cultures and as basal medium for the addition of dyes. The composition of this medium has been described (Morgan, 1960).

Basic fuchsin (supplied by Pharmaceutical Laboratories National Aniline Division, Allied Chemical and Dye Corporation, New York) was added to the melted and cooled medium just before pouring plate ${ }^{\text {ns }}$ to give a concentration of $1 / 25,000$. 
Thionin (Allied Chemical and Dye Corp.) was used at a concentration of 1/50,000. Initially, three concentrations of thionin blue (British Drug Houses Ltd., London) were used, namely, $1 / 500,000,1 / 1,000,000,1 / 2,000,000$. Later however only the $1 / 500,000$ concentration was used for routine use. Stock solutions of the dyes were made and steam sterilized. All new batches were checked for activity against known strains. All plates were incubated overnight at $37^{\circ}$ before use and no plate was used which had been stored for longer than one week in the refrigerator. The three F.A.O./W.H.O. reference strains Brucella abortus strain 544, B. melitensis strain $16 \mathrm{M}$ and $B$. suis strain 1330 , as well as $B$. abortus strain 19 were always included in each series of tests.

All cultures were tested for the requirement of additional $\mathrm{CO}_{2}$ (above that present in air) for growth, as soon as possible after isolation. Two slopes were inoculated with each isolate; one was incubated aerobically at $37^{\circ}$ and the other in an atmosphere containing $10 \%(\mathrm{v} / \mathrm{v})$ added $\mathrm{CO}_{2}$. Slopes were examined after 4 days of incubation.

For the dye sensitivity tests, cultures were incubated for $48 \mathrm{hr}$. in the $\mathrm{CO}_{2}$ enriched atmosphere and the growth suspended in buffered saline ( $\mathrm{pH} \mathrm{6.8)}$ to give a concentration of approximately $3 \times 10^{9}$ organisms $/ \mathrm{ml}$. One loopful of the suspension was streaked five times on each of the dye plates, without recharging the loop, using a quarter plate per suspension. The loop was sterilized between each plate. All the plates were incubated in the $\mathrm{CO}_{2}$ enriched atmosphere and read after 5 days of incubation at $37^{\circ}$. The results for each dye were interpreted as negative or $1+$ to $5+$ depending on whether growth had occurred on 1 or all 5 streaks.

Serological test. Monospecific sera for Brucella abortus and B. melitensis were prepared from rabbit sera by absorption with the heterologous antigen. One loopful of the serum, diluted 1/5 in phenol saline, was placed on a slide and the culture emulsified. The suspension had not to be too concentrated, otherwise agglutination was delayed. Occasionally the results of slide agglutination tests were confirmed by the tube agglutination test with monospecific sera. Suspensions of the standard strains of $\boldsymbol{B}$. abortus and $\boldsymbol{B}$. melitensis were always included as controls.

\section{RESULTS}

The pattern of results obtained with the three F.A.O./W.H.O. reference strains of Brucella, together with Brucella abortus strain 19 (the vaccine strain), is shown in Table 1. Brucella abortus strain 19 did not grow at concentrations of 1/500,000 and 1/1,000,000 of thionin blue; the reference strains $B$. abortus, B. melitensis and $B$. suis did grow at these concentrations. At the $1 / 2,000,000$ concentration of thionin blue, $B$. abortus strain 19 did grow, but in all cases gave only $2+$ to $3+$ values. Brucella melitensis and $B$. suis also showed less growth at the $1 / 500,000$ concentration of thionin blue. A number of recently isolated Brucella cultures was examined, using the three concentrations of thionin blue; a concentration of $1 / 500,000$ was eventually chosen for routine use, since this gave clear-cut results.

In Table 2 are given the results of the examination of 171 cultures of Brucella, together with their source, and it is apparent that there were three groups of Brucella abortus which did not grow on thionin blue at concentrations which allowed the growth of the majority of the strains. Of these, the largest group $(15 \cdot 2 \%$ of 

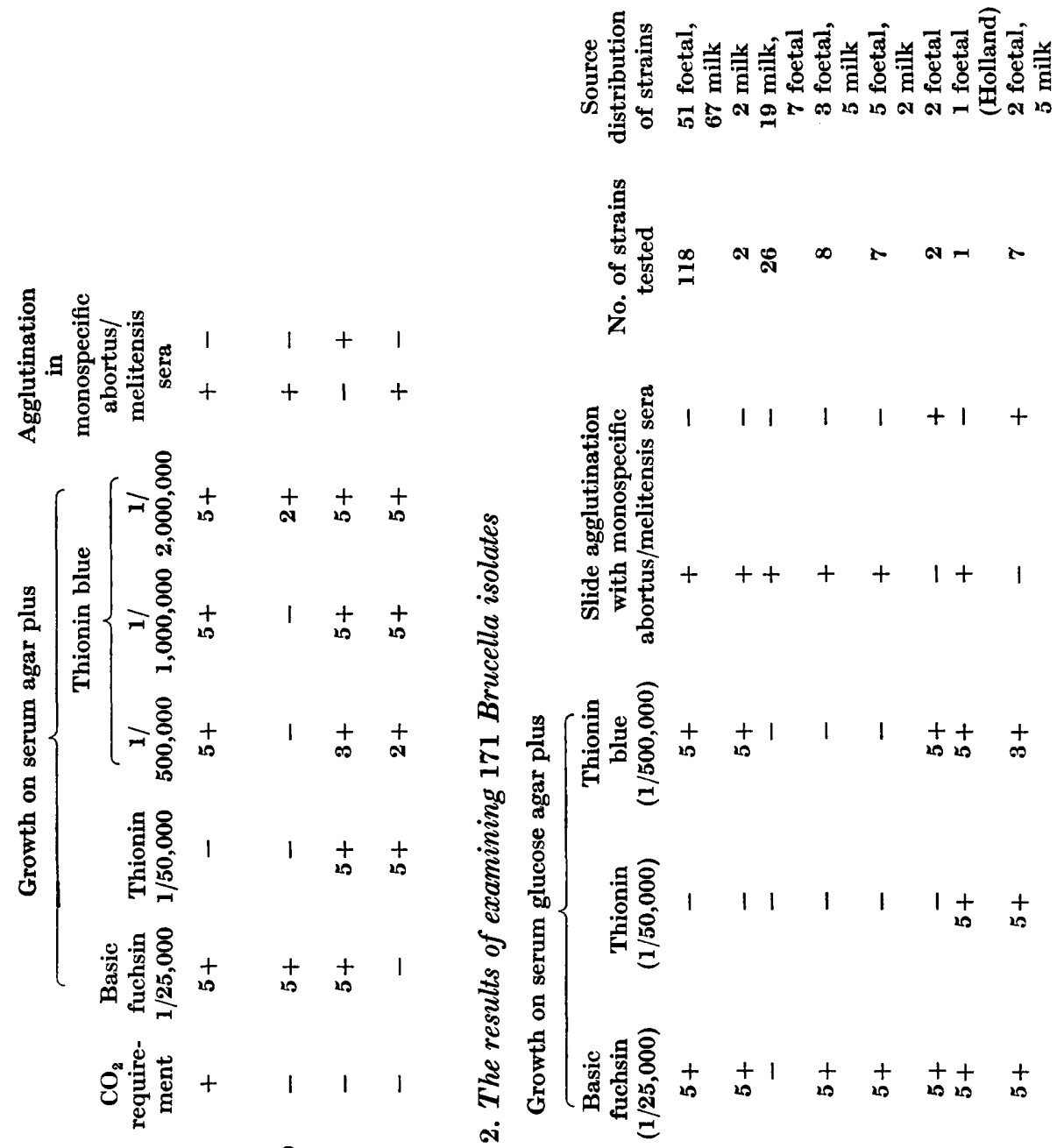

穴
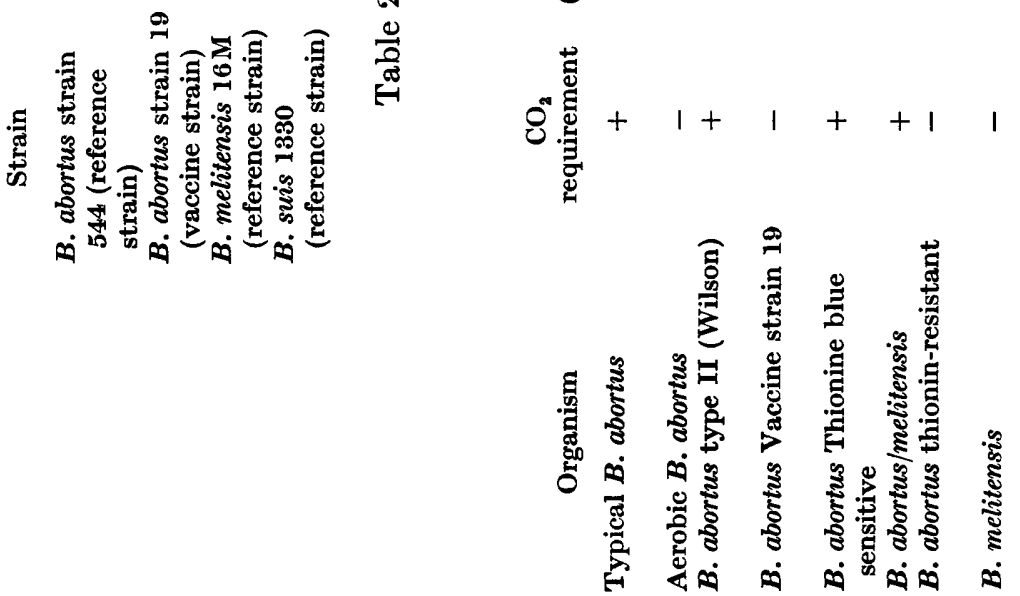
all cultures studied) belonged to the type II (Wilson). Such strains are known to be sensitive to most dyes. A second group, comprising $4.7 \%$ of all strains examined, behaved biochemically exactly like the vaccine strain $19 \mathrm{~B}$. abortus; these were recovered both from foetal material and from milk.

The third group ( $4 \cdot 1 \%$ of total isolates examined) consisted of strains that did not grow in presence of thionin blue but differed from Brucella abortus strain 19 in requiring additional $\mathrm{CO}_{2}$ for growth; but they did grow in presence of basic fuchsin, thus differing from $B$. abortus type II (Wilson). Such strains were also recovered from milk and foetal material. Most of the strains $(69 \%)$ were typical of $\boldsymbol{B}$. abortus in all their reactions, but two aerobic strains were also recovered. The other cultures consisted of $\boldsymbol{B}$. melitensis $(4 \cdot 1 \%)$ and $B$. abortus/melitensis $(2 \cdot 1 \%)$. One strain of thionin-resistant $B$. abortus was received (from Holland).

Cultures obtained from guinea-pigs and the milk of cows experimentally infected with Brucella abortus strain 19, and with the thionin blue sensitive strains of $B$. abortus in all cases behaved exactly like the strains used for inoculation, thus confirming their stability in vivo.

At the 1/500,000 concentration of thionin blue, a few colonies were observed with strain 19 and with some of the $\mathrm{CO}_{2}$ requiring thionin blue sensitive strains. After subculture on serum agar these resistant colonies gave profuse growth (5+ readings), indistinguishable from those of the standard Brucella abortus 544 on thionin blue at a dilution of 1/500,000.

\section{DISCUSSION}

Widespread vaccination of cattle with Brucella abortus strain 19 is carried out in this and other countries, and many workers have drawn attention to the need for a simple and reliable method for the differentiation of the vaccine strain from other strains of $\boldsymbol{B}$. abortus. However, no single character can be singled out as characteristic of the vaccine strain only, and it is obvious that the thionin blue sensitivity test is not pathognomonic for strain 19. In addition to $B$. abortus strain 19 and $B$. abortus type II (Wilson), a third group has now been found, also sensitive to thionin blue. Cultures of this group differ from strain 19 in that they need added $\mathrm{CO}_{2}$ for growth. Preliminary experiments at this laboratory on the virulence of cultures of the thionin blue sensitive group of $B$. abortus have shown that these are as virulent as the standard 544 strain. Virulence tests were based on the duration of bacteraemia in guinea-pigs (Cruickshank, 1957).

Since Brucella abortus strain 19 does not appear in the milk of cows after subcutaneous inoculation (Taylor \& McDiarmid, 1949) the origin of strains recovered both from milk and foetuses, and indistinguishable from strain 19, is a matter for conjecture. Some of these strains, together with strain 19, have been examined for virulence in guinea-pigs, and all have been of equally low virulence. The only conclusion appears to be that either strain 19 can appear in the milk and foetal material in some cases, or that strains occur in the field that are indistinguishable from strain 19, by our present methods.

The author wishes to thank Mr D. J. MacKinnon, B.Sc., M.R.C.V.S., for supplying most of the foetal strains of Brucella. 


\section{REFERENCES}

Cruickshank, J. C. (1954). Observations on Brucella species based on the examination of 800 strains. J. Hyg., Camb. 52, 105.

Cruickshank, J. C. (1957). The duration of bacteraemia in relation to the virulence of Brucella strains. J. Hyg., Camb. 55, 140.

Henry, B. S. (1933). Dissociation in the genus Brucella. J. infect. Dis. 52, 374.

Huddleson, I. F. (1955). The effect of bacterial cells and sonic extracts from bacterial cells in culture mediums on colonial growth of Brucella abortus. Amer. J. vet. Res. 16, 264.

HudDleson, I. F. (1956). Improvement of culture mediums for the growth and species characterization of Brucella abortus type II (Wilson). Proc. 56th General Meeting, Soc. Amer. Bact. p. 53.

Levine, H. B. \& Wilson, J. B. (1949). The identification of Brucella abortus strain 19 by dye bacteriostasis. J. infect. Dis. 84, 100.

MCLEOD, D. H. (1944). The use of thionine blue for the identification of Brucella abortus strain 19. J. comp. Path. 44, 248.

Morgan, W. J. B. (1960). A comparison of various media for the growth and isolation of Brucella. Res. Vet. Sci. 1, 51.

Sackman, W. (1957). Dye-sensitive strains of Brucella abortus type II from cows' milk. Zbl. Vet. Med. 4, 821.

TAYLOR, A. W. \& MCDiarmid, A. (1949). The stability of the avirulent characters of Brucella abortus strain 19 and strain $45 / 20$ in lactating and pregnant cows. Vet. Rec. 61, 317. 